\title{
Environmental microbiology reveals the Earth secret life
}

\author{
Denis Faure $^{1} \cdot$ Patricia Bonin $^{2} \cdot$ Robert Duran ${ }^{3}$
}

Received: 23 June 2015 / Accepted: 25 June 2015 /Published online: 11 July 2015

(C) Springer-Verlag Berlin Heidelberg 2015

Environmental microbiology investigates the diversity, dynamics, evolution, functioning, and functions of the microbes in Earth ecosystems. Environmental microbiology is born as the meet of microbiology and environmental sciences.

At the earliest times, the environmental microbiology was often associated to the applied microbiology, as attested by the existence of the reference journal Applied and Environmental Microbiology since 1952. In the 1990s, the interest of governments and scientists to the environmental sciences increased. This may be illustrated by the adoption of the United Nations Conference on Environment and Development (Rio de Janeiro, Brazil) in 1992 and the launch of the journal Environmental Science and Pollution Research in 1994. In parallel, milestones in technological advances and discoveries on microbes (diversity, functioning, and key role in ecosystem dynamics) accelerated the development of environmental microbiology as an emerging discipline (Fig. 1). Among the technologies which have reinforced the accessibility to microbes are the polymerase chain reaction (discovered by Kary Mullis in 1986, Nobel price in 1993) and, more recently,

Responsible editor: Philippe Garrigues

Patricia Bonin

patricia.bonin@mio.osupytheas.fr

1 Institut de Biologie Intégrative de la Cellule, CNRS-CEA-Université Paris-Sud, Saclay Plant Sciences, 91198 Gif-sur-Yvette Cedex, France

2 Aix Marseille Université, CNRS/INSU, Université de Toulon, IRD, Mediterranean Institute of Oceanography (MIO) UM 110, 13288 Marseille, France

3 Equipe Environnement et Microbiologie, MELODY Group, Université de Pau et des Pays de l'Adour, IPREM UMR CNRS 5254, BP 1155, 64013 Pau Cedex, France the next-generation sequencing in the 2000s (Fig. 1). Many other tools (transcriptomics, proteomics, metabolomics, imagery, isotopes...) and a tight interaction with environmental sciences also contributed to remarkable discoveries on microbes. The launch of the journal Environmental Microbiology in 1999 consecrated visibility of this discipline, which is reinforced in 2007 by the birth of The ISME journal. This journal rapidly became a flagship of the International Society of Microbial Ecology. In France, the environmental microbiology community of scientists was federated by the non-governmental "Association Francophone d'Ecologie Microbienne" (http://mio.pytheas.univ-amu.fr/AFEM/), which was created in 2004 and organizes a biennial meeting, the next being in Anglet (Aquitaine, France) in November 2015.

Since 2007, the national program "Ecosphère Continentale et Côtière" (EC2COhttp://www.insu.cnrs.fr/node/1497), which is coordinated by the CNRS (Centre National de la Recherche Scientifique), initiated a recurrent call for supporting researches in environmental microbiology. A launch funding was provided by the CNRS Mission for Interdisciplinary (http://www.cnrs.fr/mi/). From 2007 to 2015, eight annual calls allowed to supports around 1202 year starting projects (Fig. 2). Such a long-term action efficiently structures and boosts the environmental microbiology community and helps its members to access to more important national and international financial supports.

This special issue is a collection of 15 key articles selected from environmental microbiology projects funded by CNRSINSU-EC2CO, which explore the secret life of microbes in Earth ecosystem. It combines reviews and original articles reporting technical and scientific advances from the $\mathrm{EC} 2 \mathrm{CO}$ Environmental Microbiology community. The paper of Faure et al. (2015) illustrates the intense research devoted by the Microbial ecology EC2CO consortium to explore the biology, 

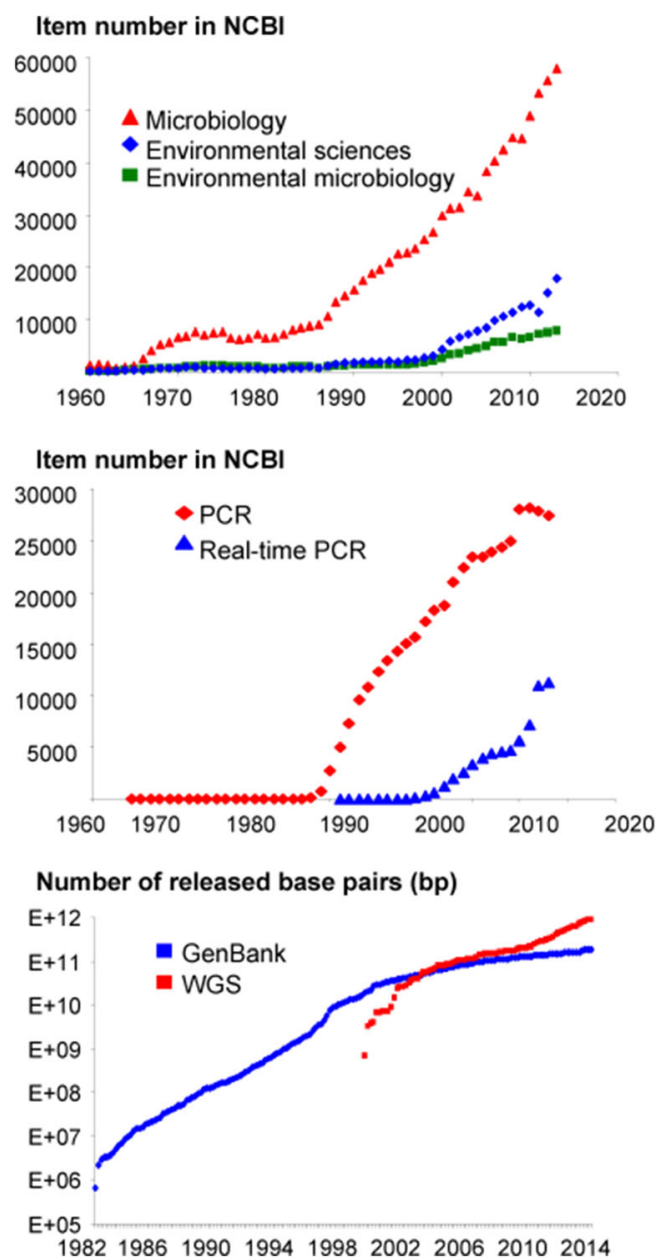

Fig. 1 Emergence of environmental microbiology. In the upper graphs, bibliometric data were collected at NCBI (www.ncbi.nlm.nih.gov/) using the items "microbiology," "environmental sciences," "environmental microbiology," "polymerase chain reaction" (PCR), and "real-time polymerase chain reaction." These analyses pointed an emergence of environmental microbiology in the 1990s with a significant impulse in the 2000s, and a strong penetration of the PCR and real-time PCR technologies since the 1990s and 2000s, respectively. The lower graph indicates the number of released base pairs (bp) of the standard and whole genome shotgun (WGS) categories over the years 1982-2014 in GenBank (http://www.ncbi.nlm.nih.gov/genbank/statistics). The number of the released bp belonging to the next-generation sequencing WGScategory is growing more rapidly than that of standard submissions

ecology, diversity, and role of microbes in aquatic and continental ecosystems. This paper is a compilation of the main contributions from around sixty starting projects. Most of them promote pluri-disciplinary approaches at the interfaces between microbial ecology, geochemistry, hydrology, ecotoxicology, biological interactions and diversity, as well as modeling in order to understand the role of microbes in the Earth critical zone. The analysis of such works clearly showed that recent technological advances of "omic" sciences allowing the high-throughput analyses of molecules (DNA, RNA, proteins, metabolites) and organisms (single cell analysis), and imagery and bioinformatic tools propelled

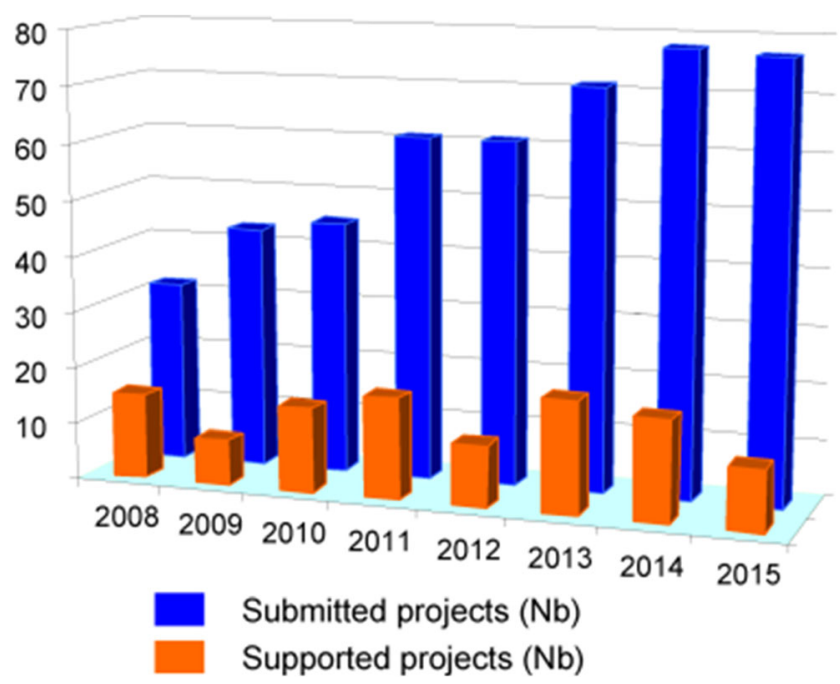

Fig. 2 Dynamics of the project submission to the environmental microbiology EC2CO call. The graph indicates the total number of submitted projects to the environmental microbiology-EC2CO call, and those that are supported over 2 years

environmental microbiology to the front line of the fastmoving and highly competitive researches. The first example is provided by the powerful scope of (meta)proteomic tools to decipher the functioning of the microbial community (ArsenePloetze et al. 2014). Today, metaproteomics are usually combined with other high-throughput "omics" methods (metatransciptomic, metabolomic) and will be probably extensively used in the next future to follow the activity of specific targeted function in complex environments. Several studies reported on the changes in microbial community metabolism and composition in diverse ecosystems: (i) in carbonate precipitates from serpentinite-hosted hyper-alkaline springs, the study of the endolithic microbial communities provided evidence of the importance of methan cycling in such ecosystem (Quemeneur et al. 2015); (ii) in coral reefs (Grange et al. 2015) described microbial communities responsible of carbonate biogenic dissolution, which is the main destructive forces; and (iii) in a Mediterranean coastal lagoon, the microbial community involved in the degradation of dissolved organic matter from jellyfish was characterized (Blanchet et al. 2014). The impact of environmental perturbations on the microbial activities was simulated in microcosms (Blanchet et al. 2014, Cea et al. 2014, Grange et al. 2015).

Three papers were devoted to microbe-microbe and hostmicrobe interactions. The role of chemical interactions in shaping microbial communities has raised increasing interest over the last decade. Many microorganisms are known to develop chemical strategies to overcome competitors, but the real importance of these interactions remains unknown. Different types of interactions are discussed. In biofilm, interactions between an allelopathic filamentous green alga, Uronemacon fervicolum and a common benthic diatom, Fistulifera saprophila were studied (Allen et al. 2014). 
Allelopathic compounds produced by the filamentous green alga impaired several functions of $F$. saprophila including growth, cell motility, adhesion, and photosynthetic activity (Allen et al. 2014). Interactions between phytoplankton and bacteria are also complex. Organic matter produced by senescent phytoplankton can be attractive for bacteria, but singlet oxygen, toxic oxygen species, generated by type II photoprocesses during the senescence of phytoplanktonic cells, is deleterious towards bacteria (Petit et al. 2015). The accumulation and concentration of various human pathogens in zebra mussels are also illustrated (Palos Ladeiro et al. 2015).

The fate of contaminants is a hot topic in the field of environmental applications. Indeed, their biodegradation by microorganisms and their availability influence their effects on living organisms - including humans - and their consequences for the functioning of ecosystems. In "contaminants" are not only the included chemical compounds of anthropogenic and natural origins, but also biological pathogens (Palos Ladeiro et al. 2015) and toxins. The emerging contaminants such as antibiotics and nanoparticles are of particular interest because their consequent presence in the environment has raised important concerns regarding their ecological impact. Laverman et al. (2015) have investigated the effect of vancomycin on denitrifying bacteria in waste water treatment plant (WWTP), receiving both domestic and hospital waste. Their results clearly demonstrated a minor effect of antibiotics towards ecosystem functioning, partly due to a change in bacterial community structure and bacterial resistance towards the tested antibiotic. Some important aspects on the impact of engineered nanoparticles on the activity, abundance, and diversity of soil microbial communities were reviewed (Simonin and Richaume 2015). The authors summarize the current state of research in this area. Of particular use is the section highlighting future research needs, covering evaluation of realistic exposures, the resilience of microbial communities, mixture toxicity, and the influence of soil physicalchemical variations.

Studies on bioremediation of hydrocarbon and metalloid compounds were reported in this special issue. The impact of various treatments (i.e., clay, amendment, organic matter from root origin, and wood sawdust addition) on aged PAH biodegradation by bacterial and fungal communities were studied in two contaminated soils (Cebron et al. 2015). Three studies are particularly devoted to the impact of metals, a topic well supported by the renewed occurrence of metals in ecosystems worldwide. The assessment of silver ion as toxic agent in river biofilm is addressed (Leflaive et al. 2014). Authors evaluated the interactive effects of silver (Ag), a reemerging contaminant, and phosphorus $(\mathrm{P})$, a nutrient often associated with freshwater eutrophication, on the structure and functioning of two types of autotrophic biofilms, one dominated by diatoms and the other by cyanobacteria. They hypothesized that $\mathrm{P}$ would alleviate the toxic effects of $\mathrm{Ag}$, either directly, through the contribution of $\mathrm{P}$ in metal detoxification processes, or indirectly, through P-mediated shifts in biofilm community compositions and associated divergences in metal tolerance. Arsenic and mercury retained special attention given their toxicity. These compounds and their derivative figure among the priority pollutants of the US EPA and the European water framework directive. Cordi et al. (2015) present the first study describing the physiological and molecular characterization of a large collection of arsenic-resistant bacteria isolates from a single site. The recent discovery of genes that code for proteins involved in $\mathrm{Hg}$ methylation raised many questions about $\mathrm{MeHg}$ production in the environment. Important concerns regarding the utility of such genes and their transcript abundance for inferring methylation rates in the environment are discussed (Goni et al. 2015).

All these projects were funded by grants from EC2CO program and the action MicroBiEn (Institut National des Sciences de l'Univers, CNRS). Authors and reviewers are greatly acknowledged for their contributions. Dr. Philippe Garrigues, editor-in-chief, is sincerely thanked for the kind invitation to publish this issue.

\section{References}

Allen JL, Ten-Hage L, Leflaive J (2014) Impairment of benthic diatom adhesion and photosynthetic activity by allelopathic compounds from a green alga: involvement of free fatty acids? Environ Sci Pollut Res Int

Arsene-Ploetze F, Bertin PN, Carapito C (2014) Proteomic tools to decipher microbial community structure and functioning. Environ Sci Pollut Res Int

Blanchet M, Pringault O, Bouvy M, Catala Pand others (2014) Changes in bacterial community metabolism and composition during the degradation of dissolved organic matter from the jellyfish Aurelia aurita in a Mediterranean coastal lagoon. Environ Sci Pollut Res Int

Cea B, Lefevre D, Chirurgien L, Raimbault Pand others (2014) An annual survey of bacterial production, respiration and ectoenzyme activity in coastal NW Mediterranean waters: temperature and resource controls. Environ Sci Pollut Res Int

Cebron A, Beguiristain T, Bongoua-Devisme J, Denonfoux Jand others (2015) Impact of clay mineral, wood sawdust or root organic matter on the bacterial and fungal community structures in two aged pahcontaminated soils. Environ Sci Pollut Res Int

Cordi A, Pagnout C, Devin S, Poirel J, Billard P, Dollard MA, Bauda P (2015) Determination of physiological, taxonomic, and molecular characteristics of a cultivable arsenic-resistant bacterial community. Environ Sci Pollut Res Int

Faure D, Duran R, Bonin P (2015) Environmental microbiology as a mosaic of explored ecosystems and issues. Environ Sci Pollut Res Int

Goni M, Corselis Y, Lanceleur L, Tessier E, Gury J, Monperrus M, Guyonneaud R (2015) Relationships between bacterial energetic metabolism, mercury methylation potential and hgca/hgcb gene expression in Desulfovibrio dechloroacetivorans beroc1

Grange JS, Rybarczyk H, Tribollet A (2015) The three steps of the carbonate biogenic dissolution process by microborers in coral reefs (New Caledonia). Environ Sci Pollut Res Int 
Laverman AM, Cazier T, Yan C, Roose-Amsaleg C, Petit F, Garnier J, Berthe T (2015) Exposure to vancomycin causes a shift in the microbial community structure without affecting nitrate reduction rates in river sediments. Environ Sci Pollut Res Int

Leflaive J, Felten V, Ferriol J, Lamy A, Ten-Hage L, Bec A, Danger M (2014) Community structure and nutrient level control the tolerance of autotrophic biofilm to silver contamination. Environ Sci Pollut Res Int

Palos Ladeiro M, Bigot-Clivot A, Aubert D, Villena I, Geffard A (2015) Assessment of toxoplasma gondii levels in zebra mussel (Dreissena polymorpha) by real-time pcr: an organotropism study. Environ Sci Pollut Res Int

Petit M, Bonin P, Amiraux R, Michotey Vand others (2015) Dynamic of bacterial communities attached to lightened phytodetritus. Environ Sci Pollut Res Int

Quemeneur M, Palvadeau A, Postec A, Monnin C, Chavagnac V, Ollivier B, Erauso G (2015) Endolithic microbial communities in carbonate precipitates from serpentinite-hosted hyperalkaline springs of the Voltri massif (Ligurian Alps, northern Italy). Environ Sci Pollut Res Int

Simonin M, Richaume A (2015) Impact of engineered nanoparticles on the activity, abundance, and diversity of soil microbial communities: a review. Environ Sci Pollut Res Int

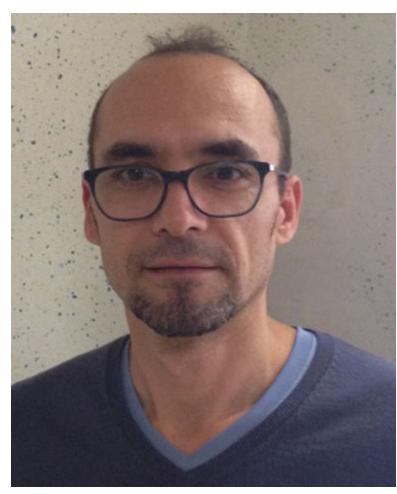

Denis Faure is a CNRS senior scientist at the Institute of Integrative Biology of the Cell (Gif-surYvette, France). He has been working for 20 years in planthost microbe and microbemicrobe interactions by combining ecology and genetics. Current research topics are devoted to bacterial communication (quorum-sensing) in the plantbacteria interactions, as well as bacterial genome structure and dynamics in plant pathogens. Since 2007, he is the co-chair of the scientific committee "Environmental Microbiology" of the French program "Ecosphère Continentale et Côtière" (EC2CO http://www. insu.cnrs.fr/node/1497). Since 2011, he is the co-chair of the French network on Environmental Genomics (http://www.cnrs.fr/inee/recherche/ actionsincitatives-RTP-Genoenvironnementale.htm).

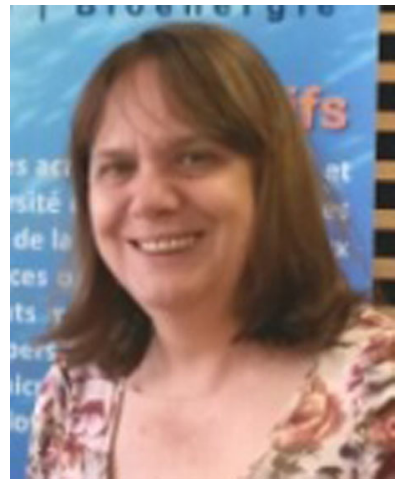

Patricia Bonin is a CNRS senior scientist at the Mediterranean Institute of Oceanography in CNRS-Aix-Marseille University joined unit. She is the head leader of a research team (Equipe Microbiologie Environnementale et Biotechnologie). She has 25year research experience in microbial ecology with particular expertise on nitrogen cycling and associated bacterial processes at the aerobic anaerobic interfaces: sediments, marine snow, or microbial mats. Her multidisciplinary approaches at the interface of biogeochemistry and microbial ecology drove significant advances in the knowledge of the ecology of this cycle. Since 2007, she is the co-chair of the scientific committee "Environmental Microbiology" of the French program "Ecosphère Continentale et Côtière" (EC2CO http://www.insu.cnrs.fr/node/1497).

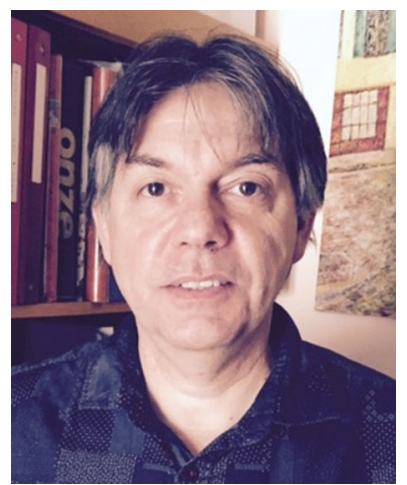

Robert Duran is a professor in Environmental Molecular Microbiology at Pau University. $\mathrm{He}$ is leading a research team (Equipe Environnement et Microbiologie) in the Institute for Analytical Sciences and Physico-Chemistry for Environment and Materials (IPREM), a CNRS-UPPA (University of Pau and Pays de l'Adour) joined unit. He has been working for 20 years in environmental microbiology and molecular microbiology research. His current research focuses on microbial ecology and diversity, with an emphasis on extreme, polluted, and estuarine and coastal ecosystems. He employs a wide range of approaches (from geochemistry to metatranscriptomics) to address fundamental and practical issues. Relevant recent discoveries include the characterization of the taxonomic and functional microbial diversity in extreme and contaminated ecosystems: behavior of sulfate reducing bacteria populations in acid mine drainage and microbial mats according to the fluctuation of environmental parameters, the diversity of ring hydroxylating dioxygenases in polluted microbial mats, and the organization of hydrocarbon-degrading prokaryotic communities in mudflat sediments. Since 2007, he is a member of the scientific committee "Environmental Microbiology" of the French program "Ecosphère Continentale et Côtière" (EC2CO http://www.insu.cnrs.fr/node/1497). 